\title{
AS CONCEPÇÕES E CONTRIBUIÇÕES DE PESTALOZZI, GRUBE, PARKER E DEWEY PARA O ENSINO DA ARITMÉTICA NO NÍVEL ELEMENTAR: O CONCEITO DE NÚMERO
}

\author{
David Antonio da Costa \\ Universidade Federal de Santa Catarina, Brasil.
}

Resumo

Este artigo aborda as concepções relacionadas ao ensino de Aritmética de Pestalozzi, Grube, Parker e Dewey. Tais concepções perpassaram os tempos e deixaram vestígios nos livros didáticos utilizados. Focalizar a investigação no conceito de número presente nos livros didáticos revela importantes contribuições destes autores na constituição da Aritmética como disciplina escolar no Brasil.

Palavras-chave: Aritmética, número, livro didático.

\section{THE CONCEPTIONS AND CONTRIBUTIONS OF PESTALOZZI, GRUBE, PARKER AND DEWEY FOR TEACHING ARITHMETIC IN ELEMENTARY LEVEL: THE CONCEPT OF NUMBER}

\begin{abstract}
This article discusses the concepts related to teaching Arithmetic of Pestalozzi, Grube, Parker and Dewey. These concepts permeate time and leave traces in the textbooks used. Focusing research on the concept of number present in textbooks reveals important contributions of these authors in the constitution of Arithmetic as school subject in Brazil.

Key-words: Arithmetic, number, textbook.

\section{LAS CONCEPCIONES Y CONTRIBUCIONES DE PESTALOZZI, GRUBE, PARKER Y DEWEY PARA LA ENSEÑANZA DE LA ARITMÉTICA EN EL NIVEL ELEMENTAL: EL CONCEPTO DE NÚMERO}

\section{Resumen}

Este artículo aborda los conceptos relacionados con la enseñanza de la Aritmética de Pestalozzi, Grube, Parker y Dewey. Estos conceptos impregnan tiempo y dejan huellas en los libros de texto utilizados. Investigación que se centra en el concepto de número presente en los libros de texto 
revela importantes contribuciones de estos autores en la constitución de la Aritmética como asignatura escolar en Brasil.

Palabras-clave: Aritmética, número, libro de texto.

\section{LES CONCEPTIONS ET CONTRIBUTIONS DE PESTALOZZI, GRUBE, PARKER ET DEWEY POUR L'ENSEIGNEMENT DE L'ARITHMÉTIQUE DANS LE NIVEAU ÉLÉMENTAIRE: \\ LE CONCEPT DE NOMBRE}

Résumé

Cet article présente les concepts liés à l'enseignement de l'Arithmétique de Pestalozzi, Grube, Parker et Dewey. Ces concepts imprègnent temps et laissent des traces dans les manuels scolaires utilisés. Recherche axée sur le concept de nombre présent dans les manuels scolaires révèle d'importantes contributions de ces auteurs dans la constitution de l'Arithmétique comme une discipline scolaire au Brésil.

Mots-clé: Arithmétique, le nombre, des manuels scolaires. 


\section{Introdução}

ste artigo aborda concepções de Pestalozzi, Grube, Parker e Dewey sobre o ensino da Aritmética presentes, a partir do século 19, nos livros didáticos no nível elementar. Este estudo foi realizado a partir da investigação de livros didáticos utilizados como corpus documental da tese de doutoramento intitulada $A$ aritmética escolar no ensino primário brasileiro - 1890-1946 ${ }^{1}$ (Costa, 2010). A maioria dos livros didáticos que foram utilizados nesta pesquisa foram obtidos na Bibliothèque Nationale de France, particularmente os do século 19.

Utilizando-se de instrumental teórico-metodológico procedente dos estudos históricos culturais, em particular do campo da história das disciplinas escolares inaugurado por André Chervel, bem como das pesquisas sobre a história do livro didático de Alain Choppin, a pesquisa se fundamentou em importantes documentos originais obtidos durante o período de estágio realizado no Institut National de Recherche Pédagogique - Service d'Histoire de l'Éducation. Isso permitiu inferir importantes contribuições acerca da história do ensino de aritmética no Brasil no final do século 19 e início do século 20.

Este artigo aborda aspectos da constituição dos conteúdos estudados na aritmética escolar, a influência de Pestalozzi no ensino elementar da aritmética, os aportes de Grube e Parker e, finalmente, as considerações de Dewey sobre a psicologia do número.

\section{A aritmética escolar}

Em um dos capítulos do livro Historia ilustrada del libro escolar em España, organizado por Agustín Escolano, os pesquisadores Modesto Sierra Vazquez, Luiz Rico Romero e Bernardo Gómez Alfonso escreveram o texto El numero y la forma: libros e impresos para la enseñanza del calculo y la geometria. Segundo estes autores, da divisão clássica das disciplinas do trivium e quadrivium correspondente às matemáticas, a Aritmética surgiu como uma destas parcelas. Desde o começo do Renascimento, concomitantemente com o surgimento da imprensa, uma grande expansão e difusão nos conhecimentos favoreceu a integração do pensamento matemático daquela época nos usos e costumes econômicos e sociais. Surgiu a aritmética prática em substituição à noção clássica da logística e, como consequência, passou-se a referir a outra parte como aritmética teórica:

A partir del siglo 19 esta diferenciación entre las aritméticas teórica y práctica desaparecerá, unificándose ambas bajo el nombre común de aritmética, reservándose las coletillas de teórica y práctica para lo que es el planteamiento teórico de conceptos y propiedades, junto con la fundamentación, cuando es posible, de algunos procedimientos en el primer caso, y lo que es la aplicación o ejecución de los procedimientos y las reglas prácticas, en el segundo. (Vazquez et al., 1997, p. 374)

Como legado dos árabes, os métodos de cálculo, derivados do sistema de numeração decimal, são essencialmente configurados como os conhecemos hoje e o uso

\footnotetext{
${ }^{1}$ A tese foi defendida no Programa de Estudos Pós-Graduados em Educação Matemática da Pontifícia Universidade Católica de São Paulo, orientada pela prof. dr. Wagner Rodrigues Valente e co-orientada pelo prof. dr. Alan Choppin durante período de estágio doutoral realizado em Paris, França, no INRP/SHE. 
dos algarismos trouxe consequências, como aponta David Smith em The teaching of elementary mathematics:

Arithmetic, at least in the Western world, was always based upon object teaching until about 1500, when the Hindu numerals came into general use. But in the enthusiasm of the first use of these symbols, the Christian schools threw away their abacus and their numerical counters, and launched out into the use of Hindu figures. And while they saw that the oldstyle objective work was unnecessary for calculation, which is true, they did not see that it was essential as a basis for the comprehension of number and for the development of the elementary tables of operation. Hence it came to pass that a praiseworthy revolution in arithmetic brought with a blameworthy method of teaching. (Smith, 1902, p. 71)

Vazquez et al (1997), ao trazer esta discussão para o âmbito dos livros didáticos de Aritmética informa que, no período que chega até o final do século 18, estes mostram diferenças significativas apenas quanto à forma de apresentação do conhecimento, além da maior ou menor exaustividade que distinguia o caráter de manual ou de tratado, de livro comercial ou erudito. O que predominava eram as apresentações de modo sistematizado dos vários modos de calcular uma mesma operação, ilustrando-as com exemplos. A ausência de argumentações, ao que se entende hoje como fundamentação, era comum nas obras deste período. Durante o século 18, na Europa, os livros dedicados à Aritmética costumavam incorporar, além dela mesma, o ensino da escrita, a gramática e a ortografia. No começo do século 19 uma mudança importante na configuração destas aritméticas escolares se produziu devido às influências recebidas da Revolução Francesa. De fato, a Revolução situou a Matemática em uma elevada posição, o que se traduziu numa ampla difusão social.

O estabelecimento de um currículo comum obrigatório aos alunos de um mesmo nível educativo implicou na necessidade da produção de livros didáticos. Estes livros se caracterizaram por um espírito elementarizador, o que se entendeu como a exposição do mais essencial, isto é, os elementos básicos do conhecimento: compêndio, postos em melhor ordem: método, de maneira mais simples: breve, e de modo mais claro para esse conhecimento ser ensinável. Esta conotação do termo essencial chegará a alterar-se posteriormente, passando a considerar-se como texto abreviado ou texto que resume um texto denso em outro mais curto. O certo é que supôs uma seleção e organização do saber, que se organizou numa proposta de ensino para as crianças na qual se incluía a Aritmética e se estabelecia o ensino do contar e as primeiras regras. Ante a Convenção Nacional Francesa, houve uma convocação para um concurso público de seleção de obras fundamentais para a instrução pública. Dos quatro textos selecionados se destaca o de Condorcet, obra chave para entender o que tem sido as aritméticas escolares (Vazquez et al, 1997).

Este livro traz três importantes contribuições:

la primera es el deseo de poner de manifesto la lógica de las reglas de cálculo y el análisis de los motivos que la sustentan; la segunda es la inclusión en el texto de sugerencias para los profesores; la tercera es un programa dividido en lecciones, las cuales, según él mismo, encierran cada una lo que es posible presentar en una sola sesión y no conviene separar en trozos. (Ibid., p. 377) 
Os conteúdos eram:

1) La numeración escrita y en cifras y los signos $+e=$. 2) El sistema de numeración oral. 3) El sistema de numeración escrito (el valor de la posición y el papel del cero). 4) Adición. 5) Sustracción. 6) Pruebas de la suma y de la resta. 7) Multiplicación, significado y productos de números de una cifra. 8) El algoritmo para multiplicar números de varias cifras. 9) División, significado y uso. División por una cifra. 10) El algoritmo de la división por números de varias cifras. 11) División inexacta. Representación del resto en forma de fracción. Forma de leer una fracción.

12) Pruebas de la multiplicación y división. (Ibid., p. 377)

Segundo Vasquez et al (1997), com o passar do tempo este programa tornou-se clássico e consolidou a identidade da Aritmética com o contar, com as quatro regras das operações e com alguns rudimentos das frações.

Outro importante fator que influenciou as aritméticas escolares é o reconhecimento da teoria da psicologia das faculdades, que considerava que a mente está constituída por diversas faculdades como imaginação, memória, percepção e raciocínio, que estas são, grosso modo, análogas aos músculos, e que, como tais, devem ser exercitados por meio de treinamentos. Neste marco de pensamento explica-se a disciplina mental como um objetivo educativo que se consegue por meio de um esforçado trabalho intelectual em torno daquelas disciplinas que se consideravam mais adequada para o treinamento da mente. Os cálculos aritméticos eram vistos como bons exercícios para fortalecer e amadurecer a mente. A grande quantidade de exercícios mentais de cálculo, aqueles que os alunos devem fazer sem o recurso de lápis e papel, tornaram-se exaustivos e marcaram aquela época (Ibid., 1997).

\section{Pestalozzi e seus métodos}

Ao final do século 18, sob a influência de Rousseau, o centro da educação começou a situar-se nos alunos. Tratava-se de conseguir não simplesmente a doutrinação do aluno, mas o desenvolvimento de suas capacidades naturais por meio dos métodos considerados mais de acordo com a natureza. A concepção do ensino começou a experimentar uma mudança que se traduziu no interesse por formular novos métodos igualmente adequados com a natureza das crianças. Certamente a figura emblemática desta busca de novos métodos mais adaptados às crianças foi Pestalozzi ${ }^{2}$, que tratou de entender e melhorar a educação popular (Eby, 1962).

Em Buisson (1887), há uma menção digna de nota:

Henri Pestalozzi tient le premier rang parmi ceux qui ont contribué à fonder la pédagogie moderne. II est naturel que ce Dictionnarie consacre um article d'une certaine étendue à l'homme au nom duquel on rattache, à tort on à raison, presque tout ce qui a été fait dans le domaine de l'éducation depuis trois quarts de siècle (Buisson, $1887, \mathrm{I}^{\mathrm{er}}, \mathrm{t}-2^{\mathrm{e}}, \mathrm{p} .979$ ).

\footnotetext{
2 Johann Heinrich Pestalozzi (1746-1827), suíço alemão nascido em Zurique, atraiu a atenção do mundo como mestre, diretor e fundador de escolas. Suas obras principais são: Leonardo e Gertrudes (1781) e Como Gertrudes instrui seus filhos (1801). Como discípulo de Rousseau estava convencido da inocência e bondade humanas e entendia que a tarefa do mestre era estimular o desenvolvimento espontâneo do aluno, procurando compreender o espírito infantil, atitude que o afasta do ensino dogmático e autoritário.
} Hist. Educ. [online] Porto Alegre v. 18 n. 42 Jan./abr. 2014 p. $37-59$ 
$\mathrm{Na}$ origem dos movimentos de renovação do ensino, a posição de Pestalozzi é geralmente associada na importância de suas idéias sobre a educação das crianças, na intuição, no uso dos objetos na aprendizagem, na educação popular. Isto é certo, principalmente, no que se refere à suas idéias acerca do número e das formas no ensino de matemática.

Comenio e Rousseau, por exemplo, também contribuíram para o desenvolvimento das idéias sobre o ensino escolar, no entanto, suas posições se manifestaram em campos distintos da Aritmética. Pestalozzi, sem dúvida, conferiu um lugar central ao número e à sua aprendizagem. Por ele novas formas de abordar o ensino da Aritmética foram propostas e seus alunos obtinham resultados surpreendentes na aprendizagem do cálculo (Gallego, 2005).

A proposta de Pestalozzi parte, como as de tantos outros reformadores do ensino, da necessidade de estender a educação a um grande número de crianças, uma vez que o sistema de ensino individual usado na época não era adequado a esse anseio. Sendo assim, Pestalozzi reconheceu a necessidade de aplicar um sistema mútuo de ensino:

Habiéndome visto obligado a instruir solo y sin auxilios a un gran número de niños, aprendí el arte de enseñar a los unos por medio de los otros, y como no tenía otro medio que la pronunciación en alta voz, concebí naturalmente el pensamiento de hacerlos dibujar, escribir y trabajar durante la clase. (Pestalozzi, 1980, p. 10)

Mas sua preocupação fundamental era descobrir um método que fosse eficaz e que pudesse ser aplicado independentemente da competência de quem atuasse como professor:

\begin{abstract}
Esto es esencial. Yo creo que no hay que pensar en avanzar un paso, en general en la educación del pueblo, mientras no se hayan encontrado las formas de enseñanza que hacen del maestro, por lo menos hasta la conclusión de los estudios elementales, el simple instrumento mecánico de un método cuyos resultados deben nacer por la naturaleza de sus formas y no por la habilidad del que lo practica. (Pestalozzi, 1980, p. 30)
\end{abstract}

O decisivo de seu aporte a este respeito é a consideração de que esse método devia basear-se no conhecimento das características das crianças, especialmente das leis psicológicas do conhecimento. Pestalozzi tratou de determinar estas leis mediante a reflexão sobre sua experiência no ensino:

Sentía que eran decisivas mis experiencias sobre la posibilidad de establecer la educación del pueblo sobre fundamentos psicológicos, de poner como base de ella conocimientos efectivos adquiridos por la intuición y desenmascarar la inanidad de ese lujo superficial de palabras de la enseñanza actual. (Ibid., p. 12)

Pestalozzi tratou de determinar estes fundamentos, que permitiriam organizar a educação da criança seguindo seu desenvolvimento progressivo de acordo com sua natureza. Em suas experiências e no esforço de determinar a origem dos conhecimentos, chegou à conclusão de que estes se encontravam no número, na forma e na palavra e que estas três questões constituiriam os meios elementares de ensino que permitiriam transformar noções confusas em noções precisas (Gallego, 2005). 
Sobre estes três meios elementares de ensino, Pestalozzi buscou os procedimentos especiais que podiam ser aplicados, os quais constituem reforma daquilo que se aplicava nas escolas de então. Tais inovações causaram fortes impressões naqueles que visitavam seu estabelecimento de ensino (Gallego, 2005).

Estas impressões tornaram-se fator importante de sua fama na época. Buisson (1887) descreve uma visita feita ao estabelecimento dirigido por Pestalozzi por um mercador alemão. A aprovação por parte deste visitante é reconhecida no texto:

Blochmann raconte dans ses Extraits de la Vie de Pestalozzi qu'un jour un riche négociant de Nuremberg vint visiter l'instituition du réformateur; il avait entendu vanter la facilité avec laquelle calculaient les élèves, et, pour s'en assurer, il demanda l'autorisation de leur poser um problème: c'était une règle de société très compliquée, à quatre proportions et où toutes les données étaient des fractions. Les enfants lui demandèrent si la question devait être résolue mentalement ou par écrit. "Mentalement, si vous l'osez", répondit-il étonné, et il prit lui-même du papier et de l'encre pour résoudre le problème. II n'en avait pás encore fait la moitié que, de tous cotes, on criait:"J'ai trouvé!" Les réponses concordaient avec le résultat qu 'il obtint quelques instants après. Se tournant vers Pestalozzi, il lui dit alors: "J'ai trois garçons, je vous les enverrai aussitôt que je serai de retour chez moi. (Buisson, 1887, p. 316)

$\mathrm{Na}$ elaboração destes procedimentos especiais, Pestalozzi buscou o desenvolvimento do ensino que estivesse de acordo com a "la marcha de la naturaleza en el desarrollo del género humano" (Pestalozzi, 1980, p. 110) e, para isso, elaborou uma série de exercícios graduados baseados na intuição.

A importância da intuição é uma das maiores contribuições de Pestalozzi: consideraa o fundamento de todo o conhecimento e o princípio da instrução que deve ser respeitado por qualquer forma de ensino que se utilize. Este princípio da intuição e a forma de levá-lo à prática tem sido um fator decisivo nas mudanças que durante os últimos séculos se tem dado ao ensino de Matemática e, em particular, no ensino de Aritmética (Gallego, 2005).

Há de se assinalar que os exercícios que elaborou não eram exercícios isolados, mas que constituíam "series graduadas y psicológicamente entrelazadas" (Pestalozzi, 1980 , p. 17), tendo em conta o desenvolvimento da criança. Pestalozzi e seus colaboradores dedicaram esforços ao descobrimento destas séries, aplicadas às noções elementares dos conhecimentos humanos e constituíram a base da aplicação de seu método e sua extensão (Gallego, 2005).

\section{O número no sistema de Pestalozzi}

El tercer medio elemental para obtener nuestros conocimientos es el número. Mas en tanto que el lenguaje y la forma emplean varios medios de instrucción subordinados a su circuito elemental para conducirnos a nociones claras y a la independencia intelectual que ellos tienen por objeto hacernos, el cálculo es el único medio de enseñanza que no comprende ningún medio subordinado; él aparece siempre, hasta el último límite de sus operaciones, como la consecuencia más sencilla de la facultad elemental que nos pone en estado de darnos cuenta cabal, en todas nuestras intuiciones, de las relaciones de cantidad, de las diferencias del 
más y del menos y de representarnos esas relaciones hasta el infinito con la precisión más clara. (Pestalozzi, 1980, p. 104)

Pestalozzi considerava o número como um dos três meios elementares para a obtenção do conhecimento e, por isto, dedicou atenção especial à sua aprendizagem. Enquanto a palavra e a forma necessitam do número para poder apresentarem-se como intuições claras, considerava o número como único meio que não tem nenhuma subordinação:

El sonido y la forma llevan a menudo y de diversas maneras en sí mismo el germen del error y de la ilusión. El número, nunca; sólo él conduce a resultados infalibles, [...] alcanza con más seguridad el objeto de la instrucción, esto es, las nociones claras, debe ser considerado como el más importante. (Ibid., p. 104)

Tendo em conta o conhecimento das leis de desenvolvimento do espírito humano, Pestalozzi afirmava que se devia praticá-lo com elevado cuidado e grande habilidade:

Ese medio de enseñanza se ha de poner generalmente en práctica y con un cuidado y una habilidad los más grandes, y que para alcanzar el último fin de la instrucción, es sumamente importante presentar este medio de enseñanza bajo formas por las cuales se pueden aprovechar todas las ventajas que pueden proporcionar en general a la enseñanza una psicología profunda y el conocimiento más vasto de las leyes del mecanismo del mundo físico. (lbid., p. 105)

Pestalozzi considerava a intuição como fundamento de seu método e organizou o estudo da Aritmética mediante o elenco dos seguintes conteúdos do ensino, condicionados pelo princípio da intuição:

La enseñanza estaba condicionada por el principio de intuición: se estudiaban aquellas cuestiones aritméticas que ejemplificaban la importancia de este principio. Por tanto, se insiste en: el aprendizaje de los primeros números; las diversas relaciones entre los números hasta el 100, expresadas de forma verba; las relaciones entre fracciones expresadas de forma verbal; la aplicación de esas relaciones a la resolución, de forma verbal, de problemas; y, sin embargo, se encuentran poças indicaciones sobre el estúdio de la aritmética escrita. (Gallego, 2005, p. 67)

A Aritmética tem sua origem na simples agregação e subtração de várias unidades. "Uno y uno son dos, y uno de dos resta uno" (Pestalozzi, 1980, p. 105), esta é considerada por Pestalozzi a forma fundamental da Aritmética. O número é considerado como a abreviação de uma agregação de unidades e o aluno somente terá uma noção clara de cada número quando, além de seu nome e de seu símbolo, o reconheça como constituído por unidades, que Pestalozzi apresenta organizadas de diferentes formas.

O ensino elementar apresentava o número como o som de uma palavra lida ou repetida de cor, memorização, de séries numéricas ou ainda como um símbolo. Pestalozzi criticava essa prática por considerá-la uma aprendizagem de palavras vazias:

Si, por ejemplo, aprendemos únicamente de memoria: tres y cuatro son siete, y en seguida contamos con ese siete como si supiésemos realmente 
que tres y cuatro son siete, nos engañamos a nosotros mismos, porque no tenemos ninguna idea de su verdad intrínseca, por cuanto no tenemos conciencia de su fondo material, el único que puede convertir para nosotros esa palabra vacía en una verdad palpable. (Pestalozzi, 1980, p. 105)

Para ele, aprendizagem do número pela criança deveria começar pelo desenvolvimento de intuições claras sobre o mesmo, no sentido de intuições sobre a quantidade como uma propriedade das coleções e das relações entre os números derivados da composição e decomposição de quantidades.

Esta aprendizagem começava nas primeiras idades com os exercícios que Pestalozzi cita, tanto em Livro de las madres (1803), como em Cómo Gertrudis enseña a sus hijos (1801). Estes exercícios foram idealizados para serem realizados nas brincadeiras dirigidas pelas mães:

Yo comienzo por el Libro de las madres en mis esfuerzos por dar a los niños una impresión viva y durable de las relaciones de los números consideradas como variaciones reales y efectivas del aumento y de la disminución de la cantidad en los objetos que se encuentran a la vista de ellos. (Pestalozzi, 1980, p. 106)

Os primeiros exercícios indicados para as crianças consistiam em perguntar pela quantidade de múltiplas coleções: partes do corpo, objetos desenhados, dedos, pedrinhas, objetos que se tem a mão. Propunha-se que as crianças resolvessem estas questões pela contagem, que aprendiam por imitação, vendo as pessoas adultas, em particular a mãe, contar distintas coleções propostas.

Também se usava como coleções as tábuas de silabação e, dessa forma, unia-se a aprendizagem dos números ao das palavras. A aprendizagem das palavras baseava-se nos números, pois se perguntava para a criança pela quantidade de sílabas de cada palavra e pela pronúncia das quais ocupavam o primeiro lugar, o segundo lugar, etc. Aparece aqui outro tipo de exercício cuja resposta é um número ordinal, que se achava auxiliado também pela contagem neste contexto.

As primeiras coleções tinham no máximo dez elementos e sobre elas realizavam-se diferentes exercícios que pretendiam ser uma iniciação as operações aritméticas:

Colocamos una tablita y preguntamos al niño: "¿Hay aquí muchas tablitas?" - El niño responde: "No, hay sólo una." En seguida agregamos una más y preguntamos: "Una y una ¿cuántas son?" - El niño responde: "Una y una son dos." Así se continúa, y se agrega al principio sólo una cada vez, después dos, tres, etc. (Ibid., p. 106)

Posteriormente, quando o aluno compreendesse as adições de uma e uma unidade até dez e quando aprendesse a expressá-las com facilidade, retomava-se o questionário, mas variava-se a pergunta:

Cuando tú tienes dos tablitas, ¿cuántas veces tienes una tablita?"- El niño mira, cuenta y responde exactamente: "Cuando yo tengo dos tablitas, tengo dos veces una tablita. ¿Cuántas veces uno son dos?, ¿cuántas unos 
son tres?, etc. ¿Cuántas veces está contenido uno en dos?, ¿en tres? (lbid., p. 107).

Tão logo o aluno conhecesse a forma simples e elementar da adição, da multiplicação e da divisão e tivesse se familiarizado, por meio da intuição, com a natureza das formas de cálculo, procurava-se fazer, por meio de outro exercício, conhecer e tornar familiar a forma original da subtração:

Se quita una de las diez tablitas que se han sumado y se pregunta: "Cuando de diez has quitado uno ¿cuántos quedan?"- El niño cuenta, encuentra nueve y responde: "Cuando de diez he quitado uno, quedan nueve". Se quita en seguida la segunda tablita y se pregunta: "Uno quitado de nueve, ¿cuántos son?" - El niño cuenta de nuevo, encuentra ocho y responde:"Uno quitado de nueve son ocho." Así se continúa hasta el fin. (lbid., p. 107)

Procurava-se, com tais atividades, a preparação para a aprendizagem das operações aritméticas. Assim, propunham-se exercícios de aumentar ou diminuir progressivamente uma coleção, perguntando à criança pela quantidade restante, preparação da soma ou subtração, ou ainda consideravam-se as quantidades como divididas em partes de um elemento e interpretava-se a situação usando a palavra veces, como preparação da multiplicação e divisão.

Em todos os casos, para resolver estes exercícios, Pestalozzi utilizava somente a simples percepção e a contagem, ao que concede grande importância no estudo das relações entre os números:

Y cuando el niño se ha ejercitado tanto en contar con objetos materiales, y con los puntos y rayas que los sustituyen, cuando esas tablas fundadas puramente en la intuición lo permiten, el conocimiento de las relaciones reales de los números se robustece entonces tanto en su espíritu que las formas de abreviación por los números ordinarios, aun sin intuición, se hacen comprensibles para él de una manera increíble, porque sus facultades intelectuales están libres de confusión, de vacíos y de enigmas que resolver. De modo que, en el verdadero sentido de la palabra, se puede decir que el cálculo enseñado así es sólo un ejercicio de la razón y nunca un trabajo de la memoria, o un procedimiento mecánico y rutinero, pero que es un resultado de la intuición más clara y más exacta y no puede conducir sino a la adquisición de nociones claras. (Pestalozzi, 1980, p. 107)

O princípio da intuição é o princípio teórico que condiciona a forma em que se elaboravam estes exercícios e que justificavam as técnicas empregadas em sua resolução: "il faut, avant de séparer de l'objet l'idée de son nombre, que l'enfant puisse voir ce nombre étroitement lié à l'objet" (Chavannes, 1809, p. 28). Por isso, todos os exercícios propostos referem-se às coleções:

Lorsque l'enfant aura été exercé à distinguer et à nommer ainsi un, deux, trois, les différens assemblages d'objets qu'on lui présente, il ne tardera pas à observer, que les mots un, deux, trois, demeurent toujours les mêmes; tandis que, ceux de pierre, de noix, avec lesquels il les lie changent suivant qu'on lui montre les uns ou les autres de ces objets ; dèslà, il en viendra bientôt à séparer l'idée du nombre de celle de la chose, et, 
par là même, à s'élever à l'idée abstrait de la quantité, ou au sentiment net et précis du plus ou du moins, indépendant de la nature des objets qu'il a sous les yeux. (Chavannes ${ }^{3}, 1809$, p. 28)

Os exercícios sobre os dez primeiros números foram incluídos por Pestalozzi no Libro de las madres e correspondiam, portanto, ao ensino que devia dar-se as crianças em suas brincadeiras. Como o Libro de las madres era usado na escola de Pestalozzi, os exercícios comentados possivelmente deveriam ser os primeiros que realizavam seus alunos ao começar sua educação.

\section{O ensino da Aritmética em Pestalozzi}

Os exercícios sobre os dez primeiros números do Libro de las madres preparavam as crianças para começar a aprendizagem escolar da Aritmética. A partir deste momento os alunos referiam-se, fundamentalmente, aos números abstratos e o princípio de indução formulado por Pestalozzi manifestava-se nos exercícios que se realizavam, tendo como referência coleções de rabiscos com diferentes organizações, de acordo com o exercício proposto.

Estas coleções, que serviam de base intuitiva às operações com números inteiros, estavam organizadas no que Pestalozzi chamava de Tábua $n$. 1, sobre a qual se realizavam os exercícios de Aritmética. Também foram idealizadas outras duas tábuas baseadas na decomposição de um quadrado em partes iguais. Essas tábuas constituíam a base intuitiva da aprendizagem das frações e das operações com as mesmas.

\section{Aprendizagem da Aritmética com a Tábua n. 1}

Nesta tábua trabalha-se com números até cem, dando idéia das relações que existem entre eles, em particular das que nascem das composições e decomposições de coleções, assim como as de múltiplo e divisor. As relações, entre os números considerados uns como partes de outros, são representadas pelo uso de frações:

Le but de ce premier tableau est d'exercer l'enfant, $1^{\mathrm{er}}$.A voir l' unité, soit comme unité, soit comme faisant partie d'une somme d'unités. $2^{\text {ème }}$.A voir une somme d'unités, soit comme formant elle-même une unité, soit comme étant une partie d'une autre somme, et ainsi à comparer l'unité et chaque somme d'unités avec une autre somme, afin de préciser exactement leurs divers rapports. (Chavannes, 1809, p. 30)

A Tábua n. 1 é composta de coleções de rabiscos dispostas em dez filas. Cada fila consta de dez coleções iguais: as da primeira fila têm um rabisco, as da segunda fila dois rabiscos e assim até a décima fila, que contém dez rabiscos.

Por meio do uso desta tábua podem ser feitos oito diferentes tipos de exercícios, que devem ser abordados de forma sucessiva, pois formam uma graduação. Em todos

${ }^{3}$ O ideário de Pestalozzi foi difundido na França e, posteriormente, na Espanha por Alex Chavannes. Chavannes, integrante do Conselho de Canton de Vaud, foi observador na Casa de Educação de Berthoud, onde atuava Pestalozzi. Vendo a prática de suas idéias como um método, um sistema, um todo ordenado, publicou na França, em 1805, a primeira edição texto Exposé de la méthode élémentaire de $\mathrm{H}$. Pestalozzi. Tal obra foi traduzida para o espanhol em 1807 por don Eugenio de Luque, Exposición del método elemental de Henrique Pestalozzi. Para esta pesquisa foi utilizado um exemplar da segunda edição do texto francês datado de 1809. 
eles se recorre à tábua por filas, considerando as diferentes relações entre as quantidades que representam os rabiscos.

O primeiro exercício proposto, segundo Chavannes (1809), é realizado por fases. No início solicita-se que o aluno imite professor, que realiza em primeiro lugar o exercício, e reconheça que a primeira fila está constituída por coleções de um rabisco, a segunda fila por coleções de dois rabiscos, a terceira fila de três e, assim, sucessivamente.

Figura 1

Tábua n.1 de Pestalozzi.

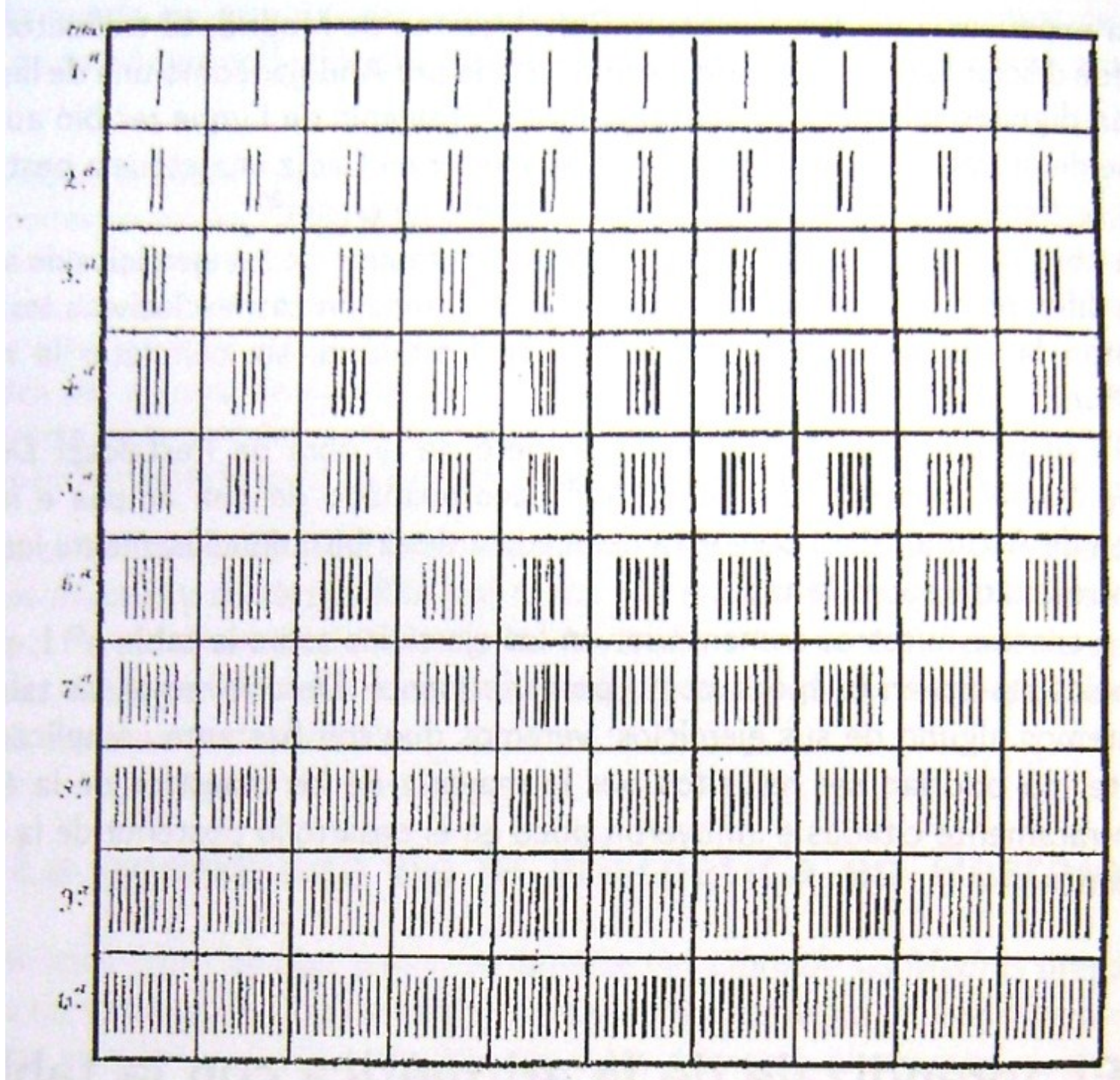

Fonte: Chavannes, 1809, p. 204.

Depois de ter sido feito este exercício em uma fila, por exemplo, na terceira, pede-se outro, que consiste em ler a fila como coleção de três elementos, isto é, uma vez o três, duas vezes o três, quatro vezes o três. 
Estes exercícios se realizam a imitação do professor, auxiliado pela contagem. A repetição destes exercícios busca sua memorização, de tal forma que o aluno seja capaz de ver quantos dois, três, quatros, etc. encontram-se em uma seção qualquer da fila.

Os demais exercícios que são apresentados no texto de Chavannes (1809) têm grau maior de dificuldade, mas tomam sempre os traços e as casas como unidades.

\section{Aprendizagem da Aritmética com a Tábua n. 2 e a Tábua n.3}

A segunda tábua compõe-se de dez filas com dez quadrados iguais em cada uma delas. As da segunda fila estão divididas em metades por um traço vertical, com os da terceira fila em terços, os da quarta fila em quartos e assim até os da décima fila, que estão divididos em décimos, sempre mediante linhas verticais.

Figura 2

Tábua n. 2 de Pestalozzi.

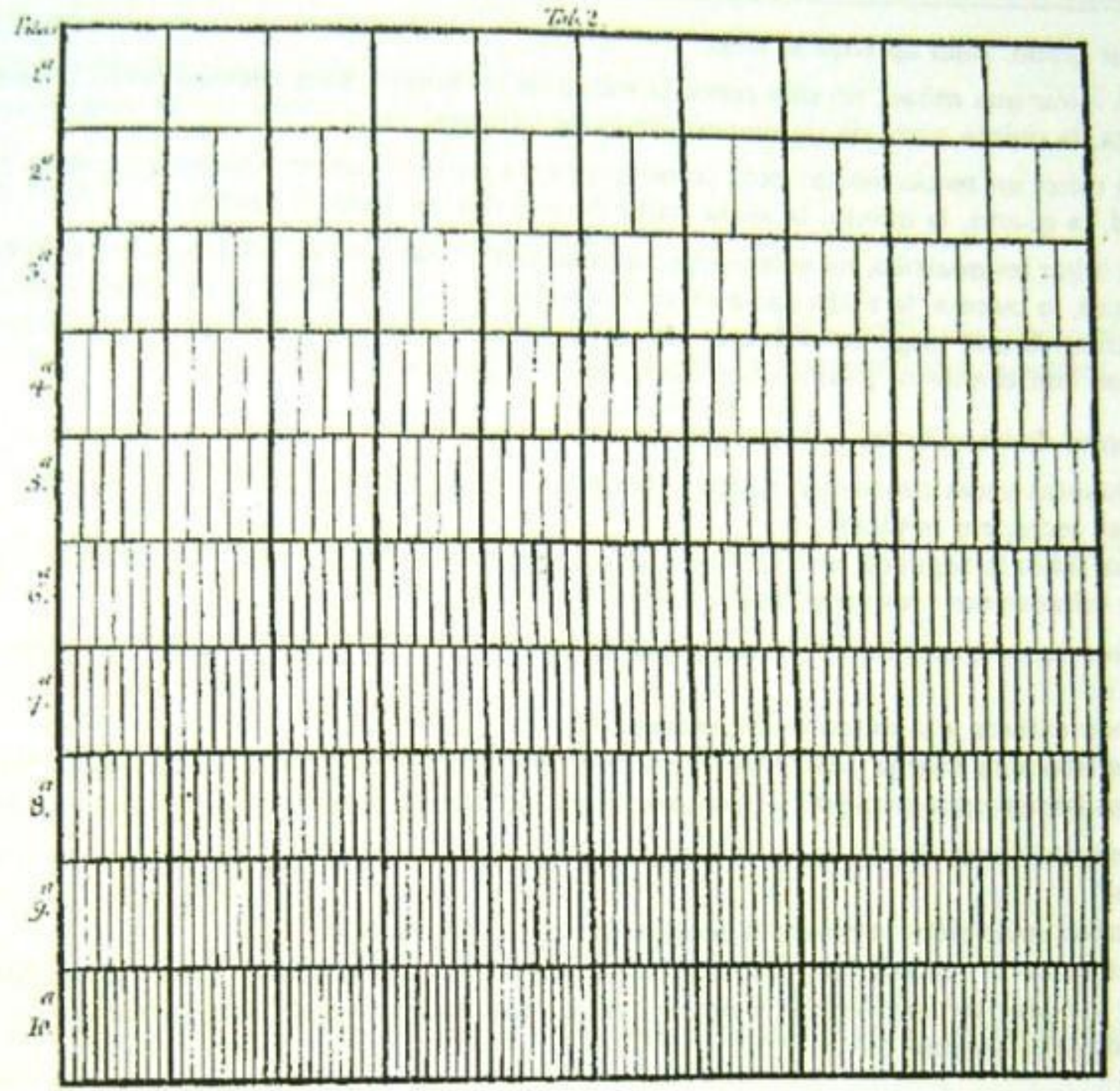

Fonte: Chavannes, 1809, p. 206. 
Sobre esta tábua realizam-se exercícios organizados em doze graus. Chavannes (1809) dá indicação sobre eles, ainda que com menor detalhe que o caso da Tábua n. 1. Os exercícios supõem recorrer à tábua, fila por fila, interpretando as diversas maneiras de cada conjunto de quadrados e partes do quadrado. Nesta segunda tábua mostram-se as unidades ao aluno como objetos divisíveis, cujas diferentes frações formam diversas partes e somas de partes de unidades. Os exercícios desta tábua são semelhantes aos da precedente, somente que adquirem uma extensão muito maior pela consideração da fração da unidade.

Figura 3

Tábua n. 3 de Pestalozzi.

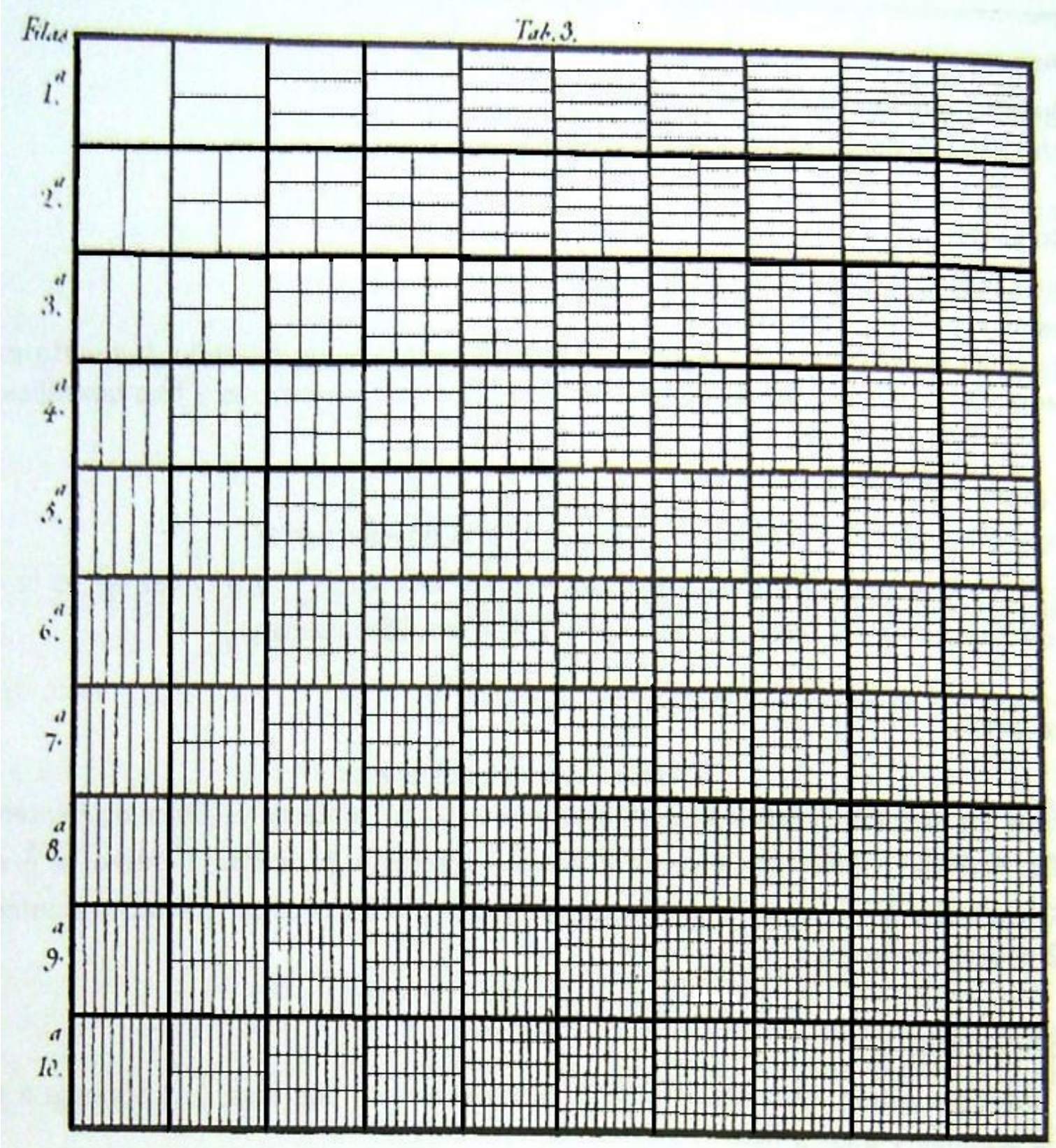

Fonte: Chavannes, 1809, p. 208. 
A Tábua n. 3 é uma ampliação da Tábua n. 2. Consta também de dez filas de dez quadrados divididos por linhas verticais da mesma forma que a Tábua $n$. 2. Além dos quadrados dividirem-se em partes iguais por linhas horizontais, os da segunda coluna em duas partes, os da terceira coluna em três, até os da décima coluna que se dividem em dez partes iguais. Com esta tábua pode-se descobrir a relação de diferentes frações e reduzir estas últimas a um denominador comum de forma mais rápida e tangível ao mesmo tempo.

Sobre esta tábua realizavam-se oito diferentes tipos de exercícios. A proposta de Pestalozzi, sobretudo no que se refere às tábuas n. 2 e 3, era demasiadamente ambiciosa para o lugar que se conferia a Aritmética na escola, o que pode explicar o porquê não se generalizaram esses exercícios. Segundo Gallego (2005), a compreensão dos exercícios que Pestalozzi propunha para as tábuas n. 2 e 3 estavam fora do alcance da maioria dos professores de primeiras letras, que apenas chegavam a conhecer algumas operações com números inteiros.

\section{O método Grube}

Após a apresentação das ideias de Pestalozzi, serão introduzidos os pensamentos de Augusto G. Grube, professor alemão que em 1842 publicou o Guia para o cálculo nas classes elementares, seguindo os princípios de um método heurístico. Tal como Pestalozzi, Grube considerava a intuição como fundamento de todo o ensino, no entanto, discordava na ordenação das matérias (Aguayo, 1966).

Segundo Buisson (1887), o cálculo intuitivo é um termo que denomina um modo de ensino dos primeiros elementos do cálculo. Esta metodologia foi criada na Alemanha, se difundiu na Rússia, Holanda, Suécia e encontrou forte aceitação nos Estados Unidos. Tal modo de ensinamento era chamado de método Grube.

Em 1842 Grube publicou, em Berlim, a primeira edição de sua Leitfaden für das Rechnen in der Elementarschule nach den Grundsätzen einer heuristischen Methode. Este Essai d'instruction éducative, como ele o chamava, depois de provocar calorosas discussões, obteve adesão da classe de professores. O tratado de Grube acertou por estar em acordo com o novo sistema de pesos e medidas e chegou, em 1873, à sua quinta edição.

O método Grube consiste em que os alunos, eles mesmos e por intuição, façam as operações fundamentais do cálculo elementar. Tal método tem por objetivo fazer conhecer os números: conhecer um objeto, que não é somente conhecer seu nome, mas vê-lo sob todas as formas, em todos os seus estados, nas suas diversas relações com outros objetos, comparar com outros, seguir nas suas transformações, escrever e medir, compor e decompor, à vontade.

Tratando os números como objetos quaisquer que se familiarizam à inteligência dos alunos, Grube opõe-se a antiga sequência do ensino em aprender sucessivamente primeiro a adição, depois a subtração, seguidas da multiplicação e divisão. As primeiras modificações dessa antiga sequência consistiam na eliminação dos números elevados agrupando-os, isto é, o ensino elementar era dividido no primeiro ano aos estudos dos números de 1 a 10, no segundo ano aos estudos dos números de 10 a 100 , no terceiro ano aos estudos dos números de 100 a 1000 e assim sucessivamente, finalizando o quarto ano com o estudo de fração. Grube, no entanto, foi além desta classificação. Ele 
descartou o uso dos números elevados, centenas e milhares, no início do curso, e ao invés de dividir o ensino dos números no primário em três ou quatro partes, isto é, de 1 à 10 , de 10 à 100, etc., considerou cada número como uma parte propriamente dita e o ensinava pelo seguinte método: recomendava que a criança deveria aprender as relações e operações de adição, subtração, multiplicação e divisão de cada número iniciado em uma seqüência desde o número 1, antes de avançar para o número sucessor (Soldan, 1878).

Tomando exemplo o número 2, Grube deixava a criança fazer todas as operações que eram possíveis dentro dos limites deste número, isto é, todas aquelas que não utilizassem os números maiores do que o próprio 2, não importando a operação que estava sendo feita. A criança deveria ter em mente que:

$$
1+1=2,2 \times 1=2,2-1=1,2 \div 1=2, \text { etc... }
$$

O completo círculo das operações até o número dois é exaustivamente feito antes de a criança ser submetida às considerações do número 3 , que é tratado da mesma forma. 
Figura 4

Método Grube, $5^{\circ}$ passo: o número 5.

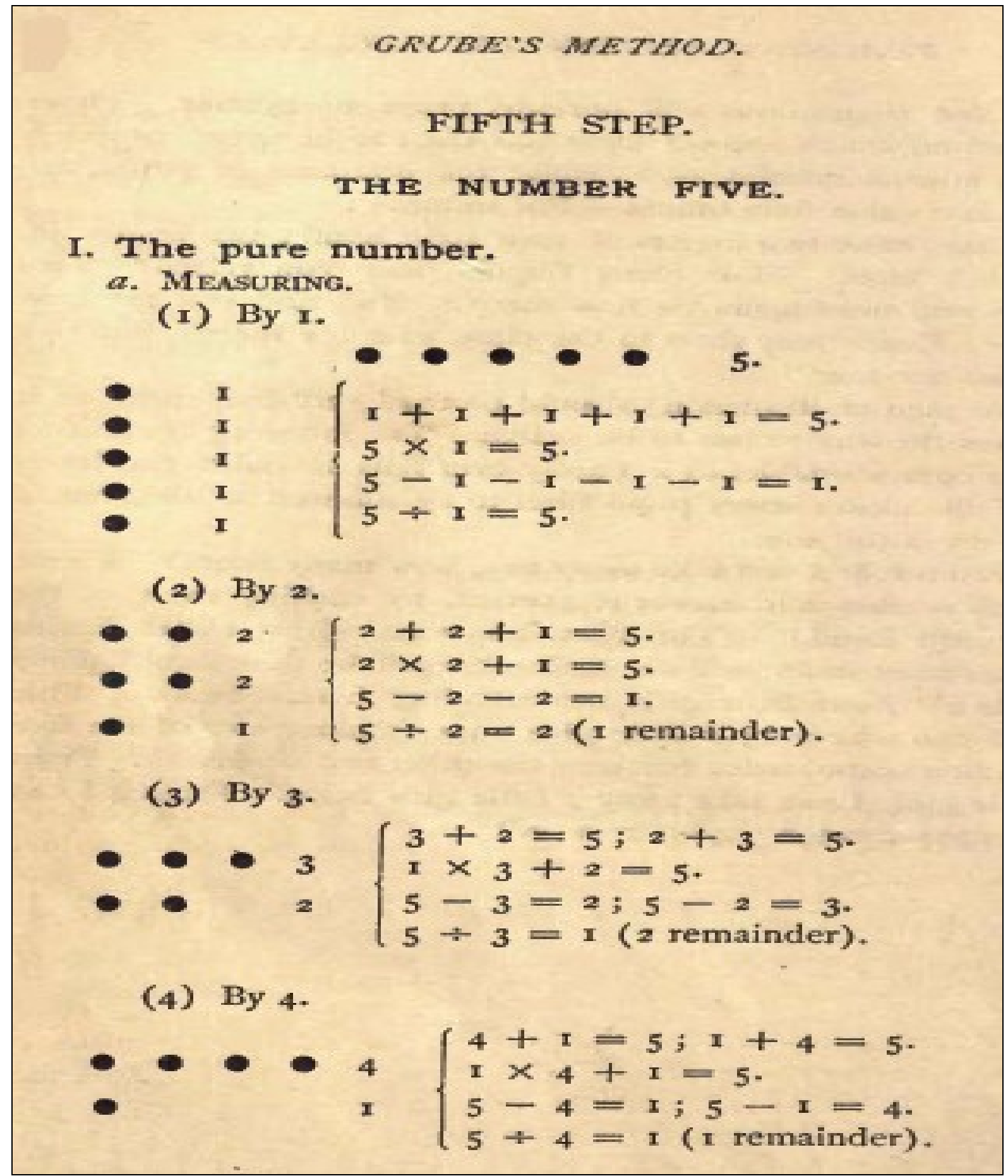

Fonte: Soldan, 1878, p.18.

Soldan (1878) indica os cinco pontos mais importantes do método Grube de ensino: a) Linguagem: linguagem é o único meio pelo qual o professor terá acesso ao que o aluno está pensando, pois não é requerido nenhum registro dos cálculos feitos por eles. Deve-se exigir do aluno uma resposta completa, pois é somente por ela que o professor poderá avaliar quanto o aluno aprendeu ou não. b) Perguntas: o professor deve evitar 
fazer muitas perguntas. Os alunos devem falar o máximo por si só. c) Recitação individual e em conjunto com a classe: no intuito de trazer animação a aula, as respostas às questões devem ser alternadamente dadas individualmente e posteriormente em grupo, principalmente seguindo o diagrama numérico ${ }^{4}$. d) llustração: cada processo e cada exemplo devem ser ilustrados por meio de objetos que deverão estar necessariamente presentes na classe. e) Comparação e medida: a operação de cada estágio consiste em comparar e medir cada novo número com o precedente, tomando lugar a relação de diferença ou de quociente, compreendendo-se as quatro regras fundamentais. Associados a esta ação, além dos chamados números puros, deve-se fazer suficientes exemplos com números aplicados ${ }^{5}$. f) Escrevendo figuras: à medida que avança o método, o aluno deve ser capaz de desenhar os diagramas numéricos.

\section{Método intuitivo e as Cartas de Parker ou diagramas numéricos}

Segundo Montagutelli (2000), Francis Wayland Parker (1837-1902) desenvolveu um sistema pedagógico que o fez reconhecido por John Dewey como pai da educação progressista. Procedente de uma família de educadores, Parker lecionava já aos dezesseis anos, tendo, posteriormente, servido ao exército na ocasião da Guerra de Secessão. Após o término da guerra, foi diretor de uma escola em Ohio. Em 1872 fez uma viagem de estudos à Europa e, na Alemanha, se familiarizou com a pedagogia de Herbart. Possivelmente nesta época tomou conhecimento do método Grube. Em 1875 retornou aos Estados Unidos e passou a ser superintendente das escolas da cidade de Quincy, em Massachusetts. Nesta época, Parker desenvolveu o chamado quincy system. Em uma atmosfera livre da rígida disciplina imposta na maioria das escolas desta época, os alunos liam jornais ou textos compostos por seus professores. Partindo do conhecido, abordavam concretamente as novas noções, seguidas de um trabalho em grupo, além de praticarem desenho e música.

Publicou cinco livros: Talks on teaching ${ }^{6}$ (New York, 1883), The practical teacher (1884), Course in arithmetic (1884), Talks on pedagogies (1894) e How to teach geography (1885).

Parker elaborou diagramas numéricos fundamentados no método Grube. Estes diagramas foram chamados de Cartas de Parker e representam a forma de tratar o ensino de Aritmética de modo intuitivo. Além disso, apresentam-se como referência para elaboração de livros didáticos de matemática destinados às séries iniciais.

\footnotetext{
${ }^{4}$ Esta parte do texto faz referência ao que será visto na seqüência como as Cartas de Parker.

${ }^{5}$ Um número puro, também chamado número abstrato, é aquele que faz menção apenas à quantidade. Quatro, trinta, doze são exemplos de números puros. Por outro lado, se houver explicitação quanto as unidades denominar-se-á número aplicado ou número concreto. Trinta maçãs, quatro árvores, três metros, são exemplos de números aplicados ou concretos.

${ }^{6}$ Este livro foi traduzido para o português por Arnaldo de Oliveira Barreto em 1909 e editado pela Livraria Casa Azul. 
Figura 5

Carta de Parker n. 4.

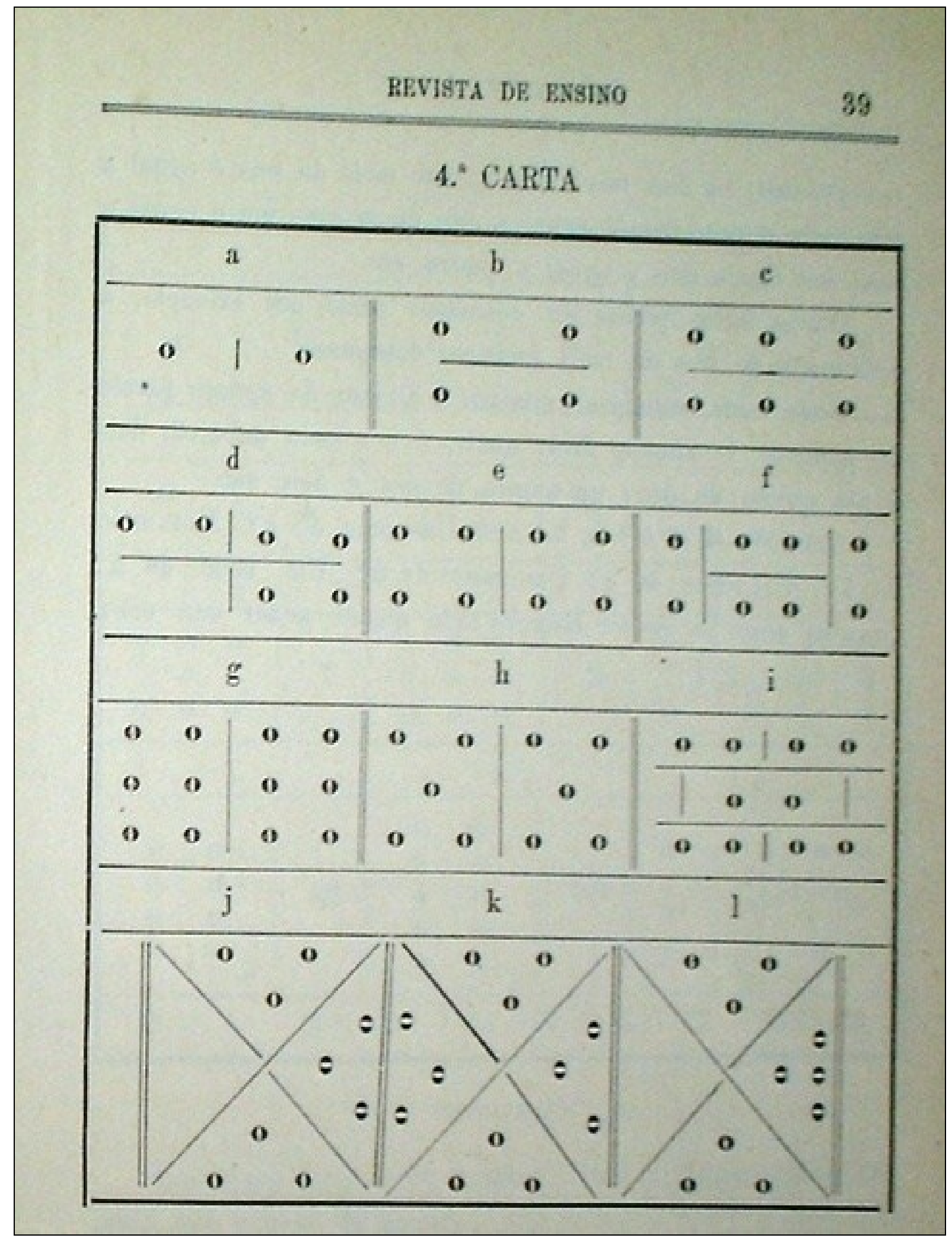

Fonte: Revista de Ensino, 1902, p. 39. 
A Revista do Ensino/SP ${ }^{7}$ publicou, ao longo de vários números, cerca de 50 dessas cartas, difundindo-as no Brasil. Por um processo heurístico, o professor questionava o aluno diante da carta. Exemplo: nos itens letras h, i e I estão desenhados a representação do número dez. Por observação o aluno é levado a responder ou a fazer suas afirmações quanto a formação deste número. Isto é, por exemplo, na letra h são necessários dois cinco para se formar um dez; na letra I encontramos o $3+3+4$ para formar o dez; assim como na letra i são necessários cinco vezes o dois para se formar um dez (Costa, 2009).

\section{Influência de Dewey: a psicologia do número}

Nos livros didáticos brasileiros de Aritmética do início do século 20 encontram-se vestígios da influência de John Dewey. Um exemplo é o texto Série graduada de matemática elementar de Barreto (1912). Segue um recorte da sexta lição:

O centimetro

(O professor deve utilizar-se dos tornos de um centimetro e de uma fitametro.) Tome um desses tornos. Que comprimento terá elle? Vamos medir. Que comprimento tem? Nina disse que tem um centimetro de comprimento. Compare o comprimento desse torno com o de outro. Que comprimento terá esse outro? Trace no quadro negro uma linha horizontal de comprimento igual ao do torno. Verifique si está certo. Que comprimento tem a linha? Trace uma linha vertical de um centimetro de comprimento. Verifique. Trace outra vertical de dois centimetros. Verifique. Trace outra horizontal tambem de dois centimetros. Verifique. Outra de um centimetro. Outra de tres. Faça uma linha longa. Meça ahi um comprimento de tres tornos e apague o resto. Que comprimento tem a linha que ficou? Faça outra linha. Meça o comprimento de quatro tornos e apague o excedente. Que comprimento tem a linha que ficou? Numa recta de trescentimetros quantos tornos pode enfileirar ponta com ponta? E numa de dois centimetros? E numa de quatro centimetros? (Barreto, 1912, p. 37)

Para Dewey (1895), o número é fruto de um processo de raciocínio e não simplesmente um fato sensível. O mero fato de que há uma multiplicidade de coisas existentes, ou ainda que esta multiplicidade esteja presente aos olhos e ouvidos, não contam para a consciência do número. Ainda que seja colocada uma criança mais velha em frente a cinco objetos e que sua atenção seja fixada nestes objetos, nada disso lhe dará a ideia do número. Número não é uma propriedade dos objetos que podem ser observáveis através do simples uso do sentido. Nenhum conceito, nenhuma ideia clara definida sobre numero pode entrar na consciência até que o pensamento seja ordenado aos objetos, isto é, comparado e relacionado entre eles de alguma forma.

A origem do número pode ser vista com uma vaga estimativa das dimensões de largura, comprimento, peso, comparadas - relacionadas - ao valor exato de uma unidade, e a repetição da qual, no espaço ou no tempo, faz assim a medida do conjunto. $O$ processo de medidas é definido em três estágios: a) medidas com uma indefinida unidade. Exemplo: medir o comprimento de uma mesa com a palma das mãos, ou ainda contar maçãs por comparação a unidade maçã; b) medidas com uma unidade propriamente definida. Exemplo: uma vez definido o comprimento de um torno por um

\footnotetext{
${ }^{7}$ Revista de Ensino da Associação Beneficente do Professorado Público de São Paulo. São Paulo: Typografia do Diario Official, 1902-1919. 
centímetro, quantos centímetros têm a mesa do professor? c) medidas com uma unidade que se relaciona a outra duas diferentes. Exemplo: não se comparam volumes e massas, porém ambas se relacionam a uma terceira unidade chamada densidade (Dewey, 1895).

\section{Considerações finais}

Numa tentativa de síntese quanto às concepções de número, pode-se dizer que a concepção mais antiga do número presente nas primeiras formas de ensino nos mostra o número apenas como o símbolo de um grupo. Aritmética era um assunto puramente utilitarista, que resumia todos os símbolos e todas as regras se regiam conforme a manipulação numérica, por exemplo, o algarismo escrito " 5 " foi sinônimo do número cinco e ensinado por um severo processo dedutivo e com base na imitação e repetição intermináveis. Os professores partidários dessa concepção, a mais antiga na história das matemáticas, não levavam em conta nenhum fim educacional e ensinavam a aritmética por processos dogmáticos.

O número pode também ser considerado como intuição sensorial. Pestalozzi foi o primeiro que se utilizou de uma base psicológica para conceituar número. Para ele, o número é mais do que um símbolo, é uma imagem mental provocada por uma experiência sensorial. Por exemplo, quatro livros são vistos, quatro moedas são apanhadas, quatro sons são ouvidos: estas impressões são guardadas no cérebro e a mente, pela correspondência um a um, as transforma na consciência de quatro. Assim como se adquire a ideia do vermelho, do áspero, do quente, a ideia do número se forma mediante a experiência de certas impressões sensoriais. Desta concepção infere-se que o número deve ser ensinado com meios concretos - dedos das mãos, ervilhas, pedrinhas, contas como fez Pestalozzi e que o melhor processo para esse fim é a operação de contar.

Mas o número também pode ser considerado como um resultado de uma relação de medida. McLellan e Dewey, no livro The psychology of number (1895), expuseram a origem e a função do número pela concepção psicológica. Esta teoria traz ao menos três contribuições a cerca do conhecimento do número: número não é uma intuição, mas uma ideia, o número é uma relação e o número é formado mediante o processo de medição.

O ensino do número, para esta concepção, está associada à medidas e comparações. Ninguém vê, nem toca, nem ouve o número 4. Pode-se ver quatro lápis, quatro cadernos, quatro livros, porque vemos os lápis, os cadernos, os livros quando estão presentes, mas não podemos, porém, aperceber-lhes o número. Quando se deseja conhecê-lo, precisa-se analisar o grupo quatro, quer dizer, contá-lo, compará-lo com o número um, ou outro que sirva de unidade, e sintetizar depois as unidades que entram neste grupo. O número não é uma imagem mental, mas a interpretação de uma experiência sensorial.

Enfim, destaca-se que a obra de Rene Barreto anunciada neste texto, a série de artigos dispostos em vários números da Revista de Ensino/SP a respeito das Cartas de Parker, a tradução do livro de Parker por Arnaldo de Oliveira Barreto, bem como a referência de Dewey nos livros didáticos de Aritmética, são fortes indícios da influência destes autores na constituição da história do ensino de Aritmética no Brasil na virada do século 19 para o início do século 20. 


\section{Referências}

AGUAYO, Alfredo Miguel. Didática da escola nova. São Paulo: Cia. Editora Nacional, 1966.

BARRETO, René. Serie graduada de mathematica elementar. São Paulo: Escolas Profissionaes Salesianas, 1912.

BUISSON, Ferdinand (dir.). Dictionnaire de pédagogie et d'instruction primaire. Paris: Hachette et $C^{\text {ie }}, 1887$.

CHAVANNES, Daniel Alexandre. Exposición del método elemental de Henrique Pestalozzi. Madrid: Imprenta de Gomes Fuentenebro, 1807.

CHAVANNES, Daniel Alexandre. Exposé de la méthode élémentaire de H. Pestalozzi, suivi d'une notice sur les travaux de cet homme célèbre, son institut et ses principaux collaborateurs. Paris: Levrault-Schoell, 1809.

COSTA, David Antonio da. Arithmetic in primary school of Brazil. In: CONFERENCE OF EUROPEAN RESEARCH IN MATHEMATICS EDUCATION, 6, Proceedings, Lyon, 2009.

COSTA, David Antonio da. Aritmética escolar no ensino primário brasileiro: 1890-1946. São Paulo: PUCSP, 2010. 282f. Tese (doutorado em Educação). Pontifícia Universidade Católica de São Paulo.

DEWEY, John; Mc LELLAM, James. The psychology of number and its applications to methods of teaching arithmetic. New York: D. Appleton and Co., 1895.

EBY, Frederick. História da educação moderna: teoria, organização e prática educacionais. Porto Alegre: Globo, 1962.

GALLEGO, Dolores Carrillo. La metodología de la aritmética en los comienzos de las escuelas normales (1838-1868) y sus antecedentes. Murcia: Departamento de Didáctica de las Ciencias Matemáticas y Sociales-Universidad de Murcia, 2005.

MONTAGUTELLI, Malie. Histoire de l'enseignement aux États-Unis. Paris: Belin, 2000.

PESTALOZZI, Juan Enrique. Cómo Gertrudis enseña a sus hijos: cartas sobre la educación de los niños. Libros de educación elemental (prólogos). México: Porrúa, 1980.

SMITH, David Eugene. The teaching of elementary mathematics. New York: Mac Millan \& Co., 1902.

SOLDAN, Frank Louis. Grube's method of teaching arithmetic: explained with a large number of pratical hints and illustrations. Boston: The Interstate Publishing Company, 1878.

VASQUEZ, Modesto Sierra; ROMERO, Luis Rico; ALFONSO, Bernardo Gómez. El número y la forma: libros e impresos para la enseñanza del cálculo y la geometría. In: BENITO, Agustin Escolano (dir.). Historia ilustrada del libro escolar en España: del Antiguo Régimen a la Segunda República. Madrid: Fundación Germán Sánchez Ruipérez/ Pirámide, 1997, p. 373-398. 
DAVID ANTONIO DA COSTA é doutor em Educação Matemática pela Pontifícia Universidade Católica de São Paulo. Docente no Centro de Ciências da Educação e no Programa de Pós-Graduação em Educação Científica e Tecnológica da Universidade Federal de Santa Catarina.

Endereço: Rua Douglas Seabra Levier, 163 - Bloco B/208 - 88040-410 Florianópolis - SC - Brasil.

E-mail: david.costa@ufsc.br.

Recebido em 18 de abril de 2013.

Aceito em 27 de outubro de 2013. 